\title{
Teleost telencephalon and memory for delayed reinforcers
}

\author{
J. BRUCE OVERMIER and RICHARD L. PATTEN \\ University of Minnesota, Minneapolis, Minnesota
}

\begin{abstract}
Past research has imputed memorial functions to the teleost telencephalon. We tested for a possible alternative basis for the past results. Groups of normal and telencephalonablated fish were trained in a discriminative choice task each under two conditions. These conditions differed in whether the delayed reinforcer was delivered under stimulus conditions similar to or different from those controlling the choice response. Ablated fish were inferior to normal fish only in the latter case. This suggests that the deficit here and in earlier work is attributable to changed stimulus conditions at the time of reinforcement rather than to delay of the reinforcer after the choice response.
\end{abstract}

Interest in and programmatic research into the functional evolution of the telencephalon has had a long but intermittent history (Flourens, 1842; Spencer, 1896; Loeb, 1902; Herrick, 1924; Lashley, 1929; MacLean, 1949; Karamyan, 1956; Prosser, 1959; Bitterman, 1960). But, despite challenges (e.g., Hodos, 1970), it again seems to be experiencing a resurgence of interest (Aronson, 1970, 1981; Brookshire, 1976; Jerison, 1973). The telencephalon of fish is anatomically the simplest among vertebrates, yet there are numerous homologies between fish and higher vertebrates (including mammals), primarily with respect to limbic structures (see Northcutt \& Bradford, 1980, and Schroeder, 1980, for recent analyses). Additionally, the telencephalon of actinopterygian fishes, such as teleosts, is of special interest because its ontogenetic development is unique among vertebrates, involving eversion of the pallial anlage rather than the usual inversion and evagination processes (Northcutt \& Bradford, 1980). Whether or not this morphologically specialized structure also implies functional diversion is a matter of controversy (e.g., Aronson, 1967, vs. Nieuwenhuys, 1967) to be resolved only by accretion and correlation of additional neurobehavioral data (see Hodos, 1970).

Ablation of the teleost telencephalon has few immediately obvious effects upon behavior (e.g., Janzen, 1933), although careful analyses have now discovered important deficits in social-reproductive behaviors and learning (see Aronson, 1970, de Bruin, 1980, Hollis \& Overmier, 1978, and Overmier \& Hollis, in press, for analytic reviews). We are especially interested in determining what psychological pro-

This research was supported by grants to J. Bruce Overmier (NSF BNS-77-28161) and to the Center for Research in Human Learning, University of Minnesota (NSF BNS-77-22075 and NICHD HD-01136). The authors' complete address is: Department of Psychology, Elliott Hall, University of Minnesota, 75 East River Road, Minneapolis, Minnesota 55455. cesses are disrupted consequent upon ablation of the teleost telencephalon. This may be achieved in part through detailed analyses of the exact pattern of competences and deficits in learning situations.

Comparisons of rates of learning by normal and telencephalon-ablated fish have now been carried out over a sufficient spectrum of learning situations to allow some generalizations and even to suggest hypotheses as to the particular psychological processes disrupted by telencephalic ablation (e.g., Flood, Overmier, \& Savage, 1976; Hollis \& Overmier, 1978; Savage, 1980). In summary, classical conditioning seems unimpaired by ablation of the telencephalon over a range of CS-US temporal relationships. Simple instrumental learning, too, seems to proceed normally in ablated fish except when there is a delay between the occurrence of the to-be-learned response and the delivery of the reinforcer. Such temporal delays result in severe impairments. Finally, avoidance learning is profoundly and nearly completely disrupted by telencephalic ablation. Analyses of these effects have led to hypothesizing of various functions for the teleost telencephalon, including that it subserves functions of (1) arousal/attention (Aronson, 1970, 1981), (2) secondary or conditioned reinforcer processing (Flood et al., 1976; Hollis \& Overmier, 1978), and (3) memory (Berintoff, 1971; Savage, 1968).

The primary purpose of the present paper is to provide further analysis of the evidentiary basis for inferring memorial functions for the teleost telencephalon. The most significant and direct evidence implicating memorial functions comes from a set of experiments by Savage in which reinforcers for responses (simple operant, discriminative choice, etc.) were delivered, not upon completion of the response, but a few seconds later (Savage, 1968, 1969; Savage \& Swingland, 1969). It is certainly true that the imposition of such delays of reinforcer impaired learn- 
ing and performance. Because learning requires temporal contiguity of the elements (or traces thereof) to be associated, this impairment is seemingly consistent with the idea that the teleost telencephalon is functionally involved in the fish's ability to maintain the memory of stimulus and response until the reinforcer is delivered.

However, recognition of operational confoundings have led us to doubt the attribution of memorial functions to the teleost telencephalon on the basis of the delay-of-reinforcer experiments. One source of confounding in these instrumental delay-of-reinforcer studies is that whenever there was a temporal delay imposed, there was also imposed a spatial separation of stimulus, response, and reinforcer. In particular, subjects had to swim several centimeters from the cued response location to a different location to obtain the delayed reinforcer. Moreover, compounded with the delay, the reinforcer was also delivered under stimulus conditions different from those for the initially required response. Research with mammals has shown that even immediate delivery of the reinforcer under stimulus conditions different from those evoking the response can impair learning, even for intact subjects (Miller \& Murphy, 1964).

The specific purpose of the present experiment is to test which of these confounded factors-temporal separation vs. spatial separation and its correlated stimulus change-is critical. Correct identification of the responsible factor is critical to the functional analysis of the teleost telencephalon. This suggests that comparison of normal and ablated fish under two different conditions of delayed reinforcer, one in which the reinforcer is delivered under stimulus conditions similar to those consequent upon responding and one in which it is delivered under conditions different from them, could provide useful information.

\section{METHOD}

\section{Subjects and Design}

Twenty-seven common goldfish (Carasius auratus), 9 to $12 \mathrm{~cm}$ in length overall and obtained from Ozark Fisheries, were the subjects of the two replications making up this experiment. Sixteen were unoperated normal fish, and 11 had undergone ablation of the telencephalon (described below). Half of the normal fish were assigned to the congruent condition (described below) and half to the irrelevant condition. Similarly, 6 of the ablated fish were assigned to the congruent condition and 5 to the irrelevant condition. This yielded a $2 \times 2$ factorial design, with factors of physiological status (normal and ablated) and stimulus conditions at reinforcement (congruent vs. irrelevant), with unequal Ns. An additional 13 fish distributed over all four treatment conditions began the experiment, but they were eliminated when they contracted a debilitating fungal infection of the skin.

\section{Apparatus}

The apparatus was patterned after that used by Grice (1948) to study the effects of delay of primary reinforcement. Our apparatus consisted of an inverted-funnel-shaped gray start chamber, $4.7 \mathrm{~cm}$ wide in the stem and $15 \mathrm{~cm}$ long, leading to two parallel alleyways. On choice trials, the fish had to choose to traverse one of

\section{Segments: "Congruent" Conditions}

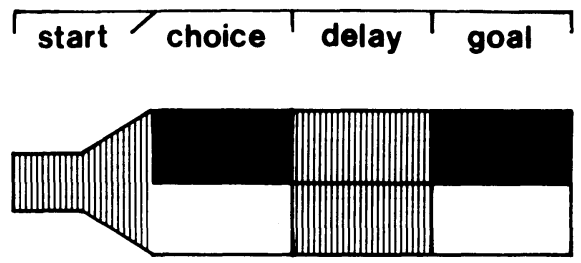

B.
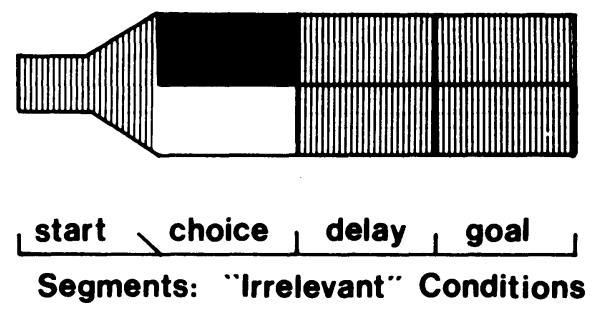

Figure 1. Illustration of the stimulus conditions existing in the parallel alleyways under the two experimental conditions, congruent (A) and irrelevant (B).

these two channels. The parallel alleyways were themselves each $4.7 \mathrm{~cm}$ wide $\times 40 \mathrm{~cm}$ long and divided into three serial $13-\mathrm{cm}$ segments, as shown in Figure 1. The first segment, the choice segment, and was black in one alley and white in the other. The alleyway in which a particular color was presented on a given trial was determined randomly. The second segment was the delay segment, and both alleyways were gray. The third segment was the goal segment, in which the reward for correct choices was given. For the two groups of fish (one ablated and one normal) under the congruent condition, these final goal segments were the same colors as the earlier choice segments, while for the two groups (one ablated and one normal) under the irrelevant conditions, the goal segments were of the neutral gray. All successive segments of the alleyways were separated from each other by vertically retracting, hand-operated opaque gates colored the same as the chamber they enclosed.

This apparatus was nested in a larger unit which allowed the subjects to await their turns for successive trials without being handled (see Flood \& Overmier, 1971). Water depth throughout was approximately $9 \mathrm{~cm}$.

\section{Operations and Verification}

The fish to be operated upon was anesthetized in a $.025 \%$ solution of tricaine methanosulfonate. The fish was then removed from the bath and placed in a special holder (Hainsworth, Overmier, \& Snowden, 1967) that allowed stabilization for extirpation and regular bathing of body and gills in the solution. Three incisions were made through the skin and skull to make a rectangular flap approximately $.4 \times .8 \mathrm{~cm}$ directly over the anterior portions of the brain. The flap was reflected, and the overlying fatty tissue and both lobes of the cerebral hemispheres were aspirated. The flap was then returned to its original position and secured with a single suture. The fish was then returned to its home tank for recovery for at least $72 \mathrm{~h}$ before further experimentation.

At the completion of the experiment, each operated fish was again anesthetized and decapitated. The head was placed in $10 \%$ Formalin for 1 week to harden. The skull was then reopened and the brain dissected out, inspected for extent of ablation, photographed, and embedded in paraplastic for histological analysis. The ablations achieved in this simple operation were very reliable, yielding complete removal of both distinct lobes of the telencephalon, leaving only the preoptic area posterior to the anterior 
commissure of the telencephalon, without damaging the optic tectum.

\section{Procedures}

Prior to the behavioral training procedures, two preliminary activities were carried out. The first of these was "habituation" to the apparatus. The subjects were placed in the apparatus and allowed to swim freely throughout for a period equal to a full daily session (approximately $2 \mathrm{~h}$ ). The second was a preference test (without reinforcement) to determine the color to which each fish preferred to swim from the start chamber. The nonpreferred color was then designated to serve as the discriminative stimulus $\left(\mathrm{S}^{\mathrm{D}}\right)$ for correct choices.

The learning portion of the experiment began the next day. Because each fish was trained against its preference, initial probabilities of correct choices were substantially less than $50 \%$. Each fish was placed in the start chamber with all gates in the lowered position. After $15 \mathrm{sec}$, the first gate was raised, exposing the discriminative choice stimuli to the fish. As the fish swam forward into one of the choice chambers, the first gate was lowered and the second one raised, giving access to the delay chamber. As the fish moved into the delay chamber, the second gate was lowered, retaining the fish in this gray midsection. After $5 \mathrm{sec}$, the third gate was raised, giving access to the goal chambers. As the fish swam into the goal chamber, the third gate was lowered. If the initial "choice" was correct, the fish was given a reinforcer consisting of .6 to $1 \mathrm{~cm}^{2}$ of flakes of TetraMin staple food. Five seconds after the fish consumed the reinforcer, it was allowed to swim out of the goal chamber into the series of waiting chambers, where it rested until its next trial approximately $20 \mathrm{~min}$ later.

On each day of training, all fish were equated with respect to their exposure to reinforced and unreinforced trials. To achieve this, each training day consisted of six trials, three of which were free-choice trials and three of which were forced-"choice" trials. The distribution of the forced trials to the reinforced or unreinforced alleyway was an inverse function of the initial free choices such that each day necessarily contained three reinforced trials to the $\mathrm{SD}$ and three unreinforced trials to the other stimulus ( $\mathrm{S}^{\Delta}$ ). Training sessions were separated by $48 \mathrm{~h}$, and the full food ration for the fish was given in the training session. Training continued until each fish had received six training blocks each of four training days (12 free choices).

\section{RESULTS}

The two replications produced the same ordering of group means of percentage correct choices at asymptote and, therefore, were analyzed together using a $2 \times 2 \times 6$ three-way ANOVA (physiological status $\times$ stimulus conditions $\times$ blocks of training days) with repeated measures on individual subjects under the last factor (Winer, 1962). The data are shown in Figure 2.

The physiological status of the fish (normal vs. ablated) did not by itself influence the results of the experiment $[F(1,23)=2.32, p>.10]$. However, the stimulus conditions at reinforcement were critical $[F(1,23)=36.25, p<.01]$, and the importance of this factor interacted significantly with the fish's physiological status $[F(1,23)=6.46, p<.05]$. The normal and the ablated fish did not differ from each other overall when the conditions at the time of reinforcement were congruent with the choice stimuli $[75 \%$ vs. $77 \%$ correct, respectively, $\mathrm{t}(23)=.29$ ], but they did differ from each other when the conditions at

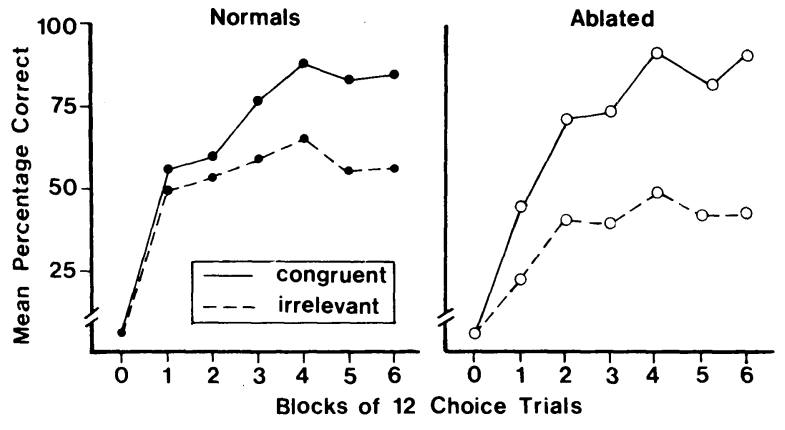

Figure 2. Mean percentages of correct choices for the four groups. The 0 point illustrates pretraining preference performance. The 0 point was not used in the data analyses but is used here only to provide a reference.

reinforcement were neutral (irrelevant) with respect to the choice stimuli [ $56.9 \%$ vs. $37.6 \%$ correct, respectively; $\mathrm{t}(23)=2.97, \mathrm{p}<.01$ ]. Importantly, while both the normal and the ablated fish learned better under the congruent condition than under the irrelevant condition [ $\mathrm{t}(23)=3.19$ and 5.71, respectively], the impairment caused by the reinforcer's being delivered under stimulus conditions different from those at the choice point was significantly greater for the ablated fish than for the normal fish $[\mathrm{t}(23)=2.37$, $\mathrm{p}<.05]$.

Finally, with respect to within-groups' performance, it might be noted that, although all groups showed some improvement in choice performance over blocks $[F(5,115)=12.66, p<.01]$, the rates of learning were significantly better under the congruent stimulus condition for both normal and ablated fish than under the irrelevant stimulus condition [stimulus $\times$ blocks, $F(5,115)=3.08, p<.05]$. Physiological status was not a determiner of rates of learning over blocks $[F(5,115)=1.34$, n.s. $]$. Nor was the three-way interaction significant $[\mathrm{F}(5,115)<1]$.

\section{DISCUSSION}

The most critical outcome of this experiment with respect to the previously reported effects of delay of reinforcement as an evidentiary basis for memorial functions of the teleost telencephalon is that physiological status, per se, was not a significant determiner of the learning. In fact, under the congruent conditions, the learning and performance of the normal and ablated groups were essentially identical despite the imposition of a 5-sec delay of reinforcer and the fact that the reinforcer was delivered at a point spatially remote from the to-be-reinforced choice response. Neither temporal remoteness nor spatial remoteness, either alone or together, differentially impaired the learning of telencephalon-ablated fish relative to normal fish.

The present finding that temporal separation is not differentially critical in instrumental response learn- 
ing is consistent with our earlier test for memorial functions. Overmier and Savage (1974) found that telencephalon-ablated fish did not differ from normal fish in their rate of classical conditioning under trace conditioning procedures in which a 5-sec CS-free gap was interposed between CS presentation and the US presentation. Farr and Savage (1978) made similar observations for trace intervals up to $15 \mathrm{sec}$. Flood (1975) has already shown long-term memory in instrumental tasks to be unaffected by telencephalon ablation.

Learning by normal and telencephalon-ablated fish was impaired by having the reinforcer delivered under stimulus conditions neutral with respect to the choice stimuli, but the ablated fish were impaired more. This observation provides a systematic replication of Savage's earlier observation that imposition of a delay of reinforcer, when coupled with the delivery of the reinforcer under stimulus conditions different from those evoking the to-be-learned response, impairs the learning and performance of ablated fish more than that of normal fish. Yet, in confirming his earlier observations, we have also demonstrated that the causal factor is not the imposed delay but the change of stimulus conditions! This finding will result in a change in thinking about the functional mechanism(s) disrupted by ablation of the telencephalon in teleosts.

This newly identified exaggerated sensitivity of telencephalon-ablated fish to stimulus differences between those surrounding the to-be-learned response and those surrounding reinforcement may also give insight into those modest deficits seen in the learning of complex mazes for food rewards (Warren, 1961) or even in L-shaped alleyways where the color of the goalbox is different from that of the alleyway itself (Flood \& Overmier, 1971). In both, the reinforcer occurs at a place remote from and distinctively different from the to-be-learned response and may well reflect the factor identified by the present experiment.

The present results indirectly address another hypothesis about teleosts' telencephalic function. Based upon analysis of deficits in avoidance learning, Flood et al. (1976) hypothesized that an important function of the teleost telencephalon was the utilization of conditioned or secondary reinforcers. Consistent with this hypothesis, Farr and Savage (1978) showed that ablated fish were impaired in their ability to use a conditioned aversive stimulus to modulate choice behavior. However, our congruent conditions represent a learning situation which should allow any differences in ability to utilize secondary reinforcers to be seen (see Grice, 1948). But it was exactly under the congruent conditions that any difference between normals and ablates failed to appear. This is not consistent with expectations based on the hypothesis concerning utilization of secondary reinforcers. While it is possible that the hypothesis remains valid, but only for conditioned aversive reinforcers, such a restriction would narrow markedly the range of phenomena for which the hypothesis could provide an explanatory base (cf. Hollis \& Overmier, 1978).

The present experiment leaves unidentified the precise functional properties of the teleost telencephalon in learning situations. However, the experimental results do reduce or limit the viability of hypotheses previously thought promising. The experiment makes clear that analysis of relative performance in learning situations by normal and ablated fish may contribute to identifying the functional properties of the CNS, but that such experiments must be sensitively instantiated with respect to the full range of factors known to modulate learning.

\section{REFERENCES}

Aronson, L. R. Forebrain function in teleost fishes. Transactions of the New York Academy of Sciences, Series 2, 1967, 29, 390-396.

Aronson, L. R. Functional evolution of the forebrain in lower vertebrates. In L. R. Aronson, E. Tobach, D. Lehrman, \& J. Rosenblatt (Eds.), Development and evolution of behavior. San Francisco: Freeman, 1970.

Aronson, L. R. Evolution of telencephalic function in lower vertebrates. In P. R. Laming (Ed.), Brain mechanisms of behaviour in lower vertebrates. Cambridge, England: Cambridge University Press, 1981.

BeritofF, J. S. Vertebrate memory: Characteristics and origin. New York: Plenum, 1971.

BitTERMAN, M. E. Toward a comparative psychology of learning. American Psychologist, 1960, 15, 704-712.

Brookshire, K. Vertebrate learning: Evolutionary divergences. In R. B. Masterton, M. E. Bitterman, C. B. G. Campbell, \& N. Holton (Eds.), Evolution of brain and behavior in vertebrates. Hillsdale, N.J: Erlbaum, 1976.

DE Bruin, J. P. C. Telencephalon and behavior in teleost fish. In S. O. E. Ebbesson (Ed.), Comparative neurology of the telencephalon. New York: Plenum, 1980.

Farr, E. J., \& Savage, G. E. First- and second-order conditioning in goldfish and their relation to the telencephalon. Behavioral Biology, 1978, 22, 50-59.

Flood, N. C. Effect of forebrain ablation on long-term retention of a food reinforced shape discrimination. Psychological Reports, 1975, 36, 783-786.

Flood, N. B., \& Overmier, J. B. Effects of telencephalic and olfactory lesions on appetitive learning in goldfish. Physiology \& Behavior, 1971, 6, 35-40.

Flood, N. C., Overmier, J. B., \& Savage, G. E. Teleost telencephalon and learning: An interpretive review of data and hypotheses. Physiology \& Behavior, 1976, 16, 783-798.

Flourens, P. Recherches experimentales sur les propriétés et les fonctions du systeme nerveux. Paris, 1842.

GrICE, G. R. The relation of secondary reinforcement to delayed reward in visual discrimination learning. Journal of Experimental Psychology, 1948, 38, 1-16.

Hainsworth, F. R., Overmier, J. B., \& Snowden, C. T. Specific and permanent deficits in instrumental avoidance responding following forebrain ablation in goldfish. Journal of Comparative and Physiological Psychology, 1967, 63, 111-116.

HERRICK, C. J. Neurological foundations of animal behavior. New York: Holt, 1924.

HoDos, W. Evolutionary interpretation of neural and behavioral studies of living vertebrates. In F. O. Schmitt (Ed.), The neurosciences: Second study program. New York: Rockefeller University, 1970. 
Hollis, K. L., \& Overmier, J. B. The function of the teleost telencephalon in behavior: A reinforcement mediator. In D. I. Mostofsky (Ed.), The behavior of fish and other aquatic animals. New York: Academic Press, 1978.

J ANZEN, W. Untersuchungen über Grosshirnfunktionen des Goldfisches (Carassius auratus). Zoologische Jahrbücher, 1933, 52, 591-628.

JERISON, H. J. Evolution of the brain and intelligence. New York: Academic Press, 1973.

KARAMYAN, A. I. [Evolution of the function of the cerebellum and cerebral hemispheres] Leningrad: Medgiz, 1956. (Trans: N.S.F., 1962, OTS-TT61-31014.)

LASHLEY, K. S. Brain mechanisms and intelligence. Chicago: University of Chicago Press, 1929.

Lовв, J. Comparative physiology of the brain and comparative psychology. New York: Putnam's, 1902.

Maclean, P. D. Psychosomatic disease and the "visceral brain": Recent developments bearing on the Papez theory of emotions. Psychosomatic Medicine, 1949, 11, 338-353.

Miller, R. E., \& MURPHY, J. V. Influence of the spatial relationships between cue, reward, and response in discrimination learning. Journal of Experimental Psychology, 1964, 67, 120-123.

Northcutt, R. G., \& Bradford, M. R. New observations on the organization and evolution of the telencephalon of actinopterygian fishes. In S. O. E. Ebbesson (Ed.), Comparative neurology of the telencephalon. New York: Plenum, 1980.

NieuwenhuYs, $R$. The interpretation of cell masses in the teleostean forebrain. In R. Hasler \& H. Stephan (Eds.), Evolution of the forebrain. Stuttgart: Georg Thieme Verlag, 1967.

Overmier, J. B., \& Hollis, K. L. The teleost telencephalon in learning. In R. G. Northcutt \& R. E. Davis (Eds.), Fish neurobiology and behavior. Ann Arbor: University of Michigan, in press.
Overmier, J. B., \& Savage, G. E. Effects of telencephalic ablation on trace classical conditioning of heart rate in goldfish. Experimental Neurology, 1974, 42, 339-346.

Prosser, C. L. Comparative neurophysiology. In A. D. Bass (Ed.), Evolution of nervous control from primitive organisms to man. Washington, D.C: American Association for the Advancement of Science, 1959.

SAvage, G. E. Function of the forebrain in the memory system of the fish. In D. Ingle (Ed.), The central nervous system and fish behavior. Chicago: University of Chicago Press, 1968.

SAvage, G. E. Some preliminary observations on the role of the telencephalon on food-reinforced behavior in goldfish, Carassius auratus. Animal Behaviour, 1969, 17, 760-772.

Savage, G. E. The fish telencephalon and its relation to learning. In S. O. E. Ebbesson (Ed.), Comparative neurology of the telencephalon. New York: Plenum, 1980.

Savage, G. E., \& Swingland, I. R. Positively reinforced behavior and the forebrain in goldfish. Nature (London), 1969, 221, 878-879.

Schroeder, D. M. The telencephalon of teleosts. In S. O. E. Ebbesson (Ed.), Comparative neurology of the telencephalon. New York: Plenum, 1980.

SPEnCER, H. The principles of psychology. New York: D. Appleton, 1896.

WarRen, J. M. The effect of telencephalic injuries on learning by the paradise fish. Macropodus opercularis. Journal of Comparative and Physiological Psychology, 1961, 54, 130-132.

Winer, B. J. Statistical principles in experimental design. New York: McGraw-Hill, 1962.

(Manuscript received January 7, 1982; accepted for publication February 10, 1982.) 